\section{Category}

Metal-Catalyzed Asymmetric Synthesis and Stereoselective Reactions

\section{Key words}

\section{palladium}

organocatalysis

synergistic catalysis

M. MEAZZA, V. CEBAN, M. B. PITAK, S. J. COLES, R. RIOS* (UNIVERSITY OF SOUTHAMPTON, UK)

Synergistic Catalysis: Enantioselective Addition of Alkylbenzoxazoles to Enals

Chem. Eur. J. 2014, 20, 16853-16857.

\title{
Enantioselective Palladium/Organo-Catalyzed Additions to Unsaturated Aldehydes
}<smiles>[R]Cc1nc2ccccc2o1</smiles><smiles>CC(C)O</smiles>

$\mathrm{Pd}(\mathrm{OAc})_{2}(5 \mathrm{~mol} \%)$ organocatalyst (20 mol\%) $\mathrm{Et}_{3} \mathrm{~N}(50 \mathrm{~mol} \%)$ $\operatorname{MeCN}(0.52 \mathrm{M}), 35^{\circ} \mathrm{C}, 14-40 \mathrm{~h}$ then $\mathrm{Ph}_{3} \mathrm{PCHCO}_{2} \mathrm{Me}$ organocatalyst<smiles>CS(C)(C)[OH+]C(c1ccccc1)(c1ccccc1)C1CCCN1</smiles>

Selected examples:<smiles>COC(=O)/C=C/C[C@@H](c1ccc(Br)cc1)C(C)c1nc2cc(Cl)c([N+](=O)[O-])cc2o1</smiles>
$99 \%$ ee (major) $/ 56 \%$ ee (minor)

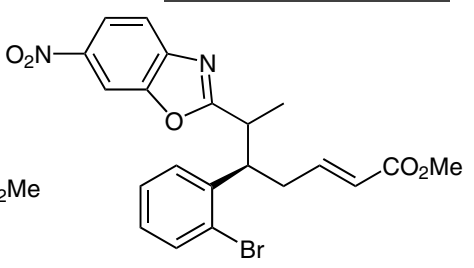

$69 \%$ yield, $d r=1.6: 1$ $85 \%$ ee (major) $/ 53 \%$ ee (minor)

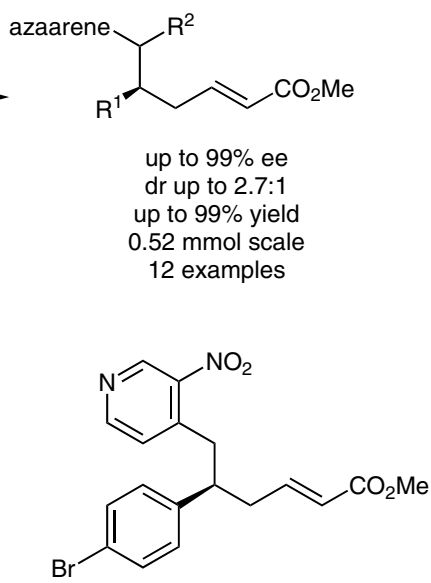

$68 \%$ yield, $89 \%$ ee Proposed mechanism

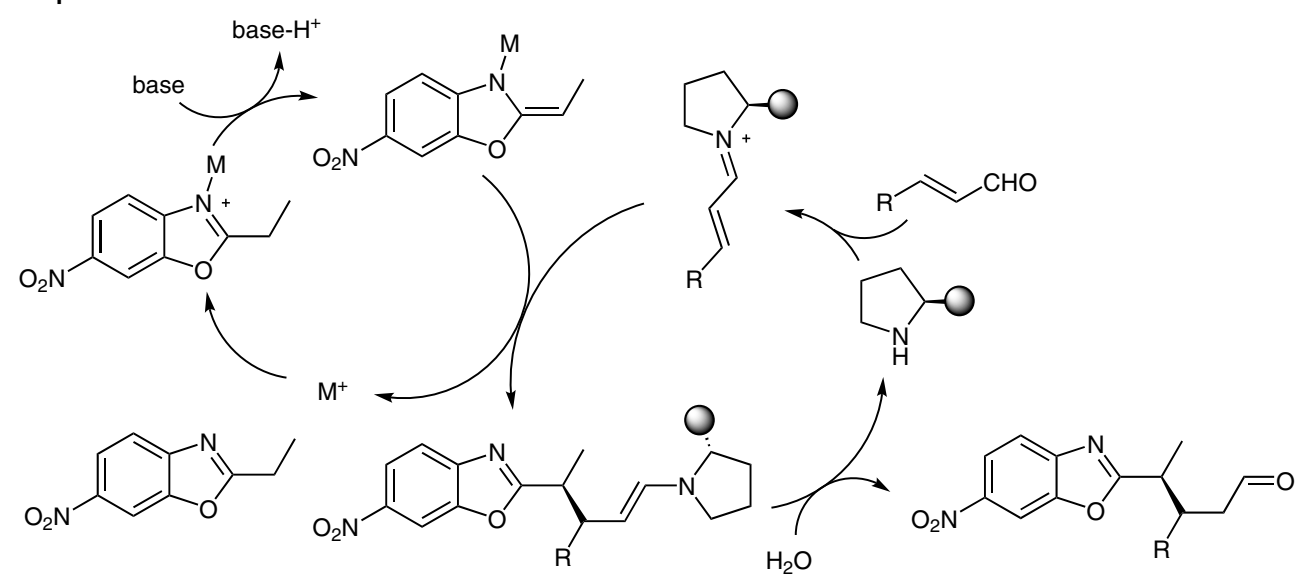

Significance: Synergistic catalysis has recently been gaining attention because the two separate catalysts can be optimized independently (see Review below). The authors present a palladium/chiral secondary amine catalyzed reaction between azaarenes and unsaturated aldehydes.

Review: A. E. Allen, D. W. C. MacMillan Chem.

Sci. 2012, 3, 633-658.

SYNFACTS Contributors: Mark Lautens, Zafar Qureshi

Synfacts 2015, 11(1), 0066 Published online: 15.12.2014

Dol: 10.1055/s-0034-1379691; Reg-No.: L15714SF

Comment: Although diastereoselectivity was poor (highest ratio 2.7:1), good enantioselectivities were observed for both major and minor isomers. The palladium acts as a Lewis acid to activate the azaarene, whereas the proline-derived organocatalyst activates the aldehyde towards 1,4-addition. 